\title{
Narrativa Transmidia: modos de narrar e tipos de histórias
}

Transmedia Storytelling: ways of narrating and types of stories

Camila Augusta Pires de Figueiredo

Universidade Federal de Minas Gerais, Belo Horizonte, MG, Brasil

Resumo: Há alguns anos, nota-se uma tendência em produções contemporâneas de se envolverem em uma rede em que a história se desdobra em múltiplas plataformas e em que várias mídias convergem e se entrelaçam, condição que é chamada de transmídia. A narrativa transmídia designa a utilização de várias plataformas midiáticas que convergem para contar uma história, sendo que cada novo texto contribui de forma distinta para tal. Este estudo examina o modo como a narrativa transmídia narra histórias, bem como os tipos de histórias que normalmente são contadas por meio da narrativa transmídia.

Palavras-Chave: narrativa transmídia; narrativa transmidiática; transmidialidade.

Abstract: For some years now, we have observed a tendency in contemporary productions to get involved in a network in which the story unfolds across multiple platforms and several media converge and intertwine, a condition that is called transmedia. Transmedia narrative designates the use of several media platforms that converge in order to tell a story, in which each medium makes a unique contribution to that. This study examines the way transmedia narrative narrates stories, as well as the kinds of stories that are normally told by means of transmedia narrative.

Keywords: transmedia storytelling; transmedia narrative; transmediality.

Há alguns anos, nota-se uma tendência em produções contemporâneas de se envolverem em uma rede em que a história se desdobra em múltiplas plataformas e em que várias mídias convergem e se entrelaçam, condição que é chamada de transmídia. Atento a esse novo contexto multimidiático, Henry Jenkins aponta que, desde o final da década de 1970, mudanças tecnológicas e econômicas fizeram surgir na indústria do entretenimento um novo tipo de produto, denominado franquia. Nesse tipo de produção, o conteúdo não se concentra somente em uma mídia, mas projeta-se por meio de extensões 
e espalha-se através de outras mídias e de produtos licenciados, em um "empenho coordenado em imprimir uma marca e um mercado a conteúdos ficcionais" (JENKINS, 2009, p. 47). As franquias se inserem em um novo panorama cultural contemporâneo, chamado por Henry Jenkins de "cultura da convergência", que abrange os "fluxos de conteúdo através de múltiplas plataformas de mídias [e a] cooperação de múltiplos mercados midiáticos" (Ibidem, p. 29).

Um elemento muitas vezes presente nas franquias é a narrativa

Camila transmídia. ${ }^{1}$ De acordo com Elizabeth Evans, o termo "narrativa transAugusta Pires de Figueiredo mídia" [transmedia storytelling] foi utilizado pela primeira vez por Marsha Kinder e Mary Celeste Kearney como uma prática promocional envolvendo merchandising, adaptações, sequências e franquias (EVANS, 2011, p. 20-21). Para Jenkins, a narrativa transmídia designa a utilização de várias plataformas midiáticas que convergem para contar uma história, sendo que cada novo texto contribui de forma distinta para tal. Uma vez que um único texto não conseguiria abranger todo o conteúdo da narrativa, um texto central oferece vários pontos de acesso ao enredo, pontos esses que são explorados em outras mídias tais como jogos digitais, histórias em quadrinhos, sites, vídeos online, blogs, redes sociais etc. Assim, através da narrativa transmídia, pode-se, por exemplo, desenvolver histórias de personagens secundários, apresentar outras perspectivas da narrativa, completar "buracos" da história, ou ainda fazer uma ponte entre um filme e sua sequência. No caso de narrativa transmídia ideal, não há redundância de informações, mas cada mídia oferece novos níveis de revelação, que se juntam para compor a narrativa completa da franquia.

O termo "narrativa transmídia" ganhou popularidade na última década na indústria cultural e do entretenimento e tem sido amplamente utilizado por artistas, produtores, marcas, desenvolvedores de jogos, críticos e estudiosos. A definição mais comumente utilizada para caracterizar o fenômeno transmidiático é a que Henry Jenkins propõe em 2003 na coluna para a Technology Review, ${ }^{2}$ cujos parâmetros foram posteriormente retomados em seu livro Cultura da convergên-

\footnotetext{
1 Manterei a tradução de Susana Alexandria para o termo "transmedia storytelling" de "narrativa transmídia" (e seu plural, "narrativas transmídia"), exatamente como no livro Cultura da convergência. No entanto, optei pela palavra "transmidiático(a)" como adjetivo de outras expressões.

2 Disponível em <https://www.technologyreview.com/s/401760/transmedia-storytelling/>. Acesso em: 14 jan. 2016
} 
cia. ${ }^{3}$ Para ele, a transmídia designa um novo tipo de narrativa, em que a história "se desenrola por meio de múltiplas plataformas de mídia, com cada novo texto contribuindo de maneira distinta e valiosa para o todo" (JENKINS, 2009, p. 138). De acordo com Jenkins, esse fluxo de conteúdo através de múltiplos canais de mídia é quase inevitável nesta era de convergência de mídias.

A transmídia se apoia em uma tríade: a convergência dos meios de comunicação, a cultura participativa e a inteligência coletiva. A convergência dos meios de comunicação se dá por meio dos "fluxos de conteúdo através de múltiplas plataformas de mídias", da "cooperação entre múltiplos mercados midiáticos" e do "comportamento migratório dos públicos dos meios de comunicação"; a convergência não se dá pela união de aparelhos, mas "ocorre dentro dos cérebros dos consumidores individuais e em suas interações sociais com outros" (Ibidem, p. 29-30). A cultura participativa contrasta com a noção de passividade do público, que abandona o papel de simples consumidor de produtos de mídias e passa a participar, interagir e até mesmo produzir seu próprio conteúdo midiático. A expressão "inteligência coletiva", cunhada pelo teórico francês Pierre Lévy, refere-se à estratégia de consumo encontrada para fazer frente ao grande fluxo de informações dos nossos dias: “[p]or haver mais informações sobre determinado assunto do que alguém possa guardar na cabeça, há um incentivo extra para que conversemos entre nós sobre a mídia que consumimos." (Ibidem, p. 30). Primeiramente, as informações são coletadas conforme os recursos e habilidades individuais; posteriormente, de modo semelhante ao que fazemos com as peças de um quebra-cabeças, esses pedaços de informação são unidos.

Em seu blog Confessions of an Aca-Fan, Jenkins descreve o fenômeno como "uma lógica para pensar sobre o fluxo de conteúdo que atravessa mídias" (JENKINS, 2011). ${ }^{4} \mathrm{Na}$ prática, portanto, a narrativa transmídia é uma estratégia normalmente utilizada para (a) fazer uma ponte entre um texto principal - geralmente o filme - e suas sequências; (b) prenunciar evoluções no enredo de uma obra; (c) expandir a narrativa ou completar suas lacunas; (d) desenvolver histórias de

3 Em inglês: Convergence Culture: Where Old and New Media Collide. New York: NYU Press, 2006. Em português: Cultura da convergência. São Paulo: Aleph, 2008 ( (1ª edição) e 2009 (2ª. edição, ampliada e atualizada). 4 “(...) one logic for thinking about the flow of content across media." (Disponível em: <http://henryjenkins.org/2011/08/defining_transmedia_further_re.html>. Acesso em: 14 jan. 2016) 
personagens secundários, outros detalhes e perspectivas da narrativa; (e) oferecer um apoio para o ingresso de um novo público à franquia; (f) construir universos que não podem ser esgotados em uma só mídia. Economicamente, trata-se de um projeto vantajoso para os produtores, pois acaba por conquistar consumidores de diferentes nichos $\mathrm{e}$ aumentar o engajamento do público.

Uma das áreas de pesquisa que têm como objeto de estudo a narrativa transmídia é a narratologia. A narratologia dedica-se ao Camila estudo da representação das práticas e princípios da narrativa. ApeAugusta Pires de Figueiredo sar de suas origens estarem associadas ao estudo da narrativa em textos verbais, em especial à prosa literária, ${ }^{5}$ hoje uma das abordagens é a intermidiática, que examina a narrativa em qualquer mídia - literatura, cinema, quadrinhos, video games etc. Assim, pode-se questionar, por exemplo, que tipos de histórias são contadas por uma mídia; quais propriedades de uma determinada mídia são favoráveis ou desfavoráveis à narratividade; o que uma mídia pode fazer que a outra não pode; que gêneros, instrumentos ou problemas narrativos são particulares a uma mídia; e sob que condições as mídias não verbais podem contar histórias.

Para a narratologista Marie-Laure Ryan, estudar narrativas em várias mídias implica compreendê-las como uma representação mental e cognitiva e não apenas como um ato de comunicação verbal. A autora explica que, especialmente após Roland Barthes e Claude Bremond, a narrativa se emancipou da literatura e passou a ser reconhecida como "um fenômeno semiótico que transcende disciplinas e mídias" (RYAN, 2005, p. 344). ${ }^{6}$ Essa noção de narrativa é relevante por dois motivos: primeiro, porque abre espaço para analisar a narratividade presente em mídias que necessariamente não usam o verbal para narrar, como a dança, a música, ou pinturas. Afinal, "existem significados que simplesmente são transmitidos mais efetivamente por meio visual ou musical do que verbalmente" (RYAN, 2004 , p. 12); ${ }^{7}$ segundo, porque, como acontece em vários projetos transmidiáticos, não apenas as sequências de eventos são narradas,

\footnotetext{
5 Para uma descrição mais detalhada dos conceitos e da história da narratologia, ver o verbete "Narratology", de Jan Christoph Meister, no âmbito do projeto the living handbook of narratology, da Universidade de Hamburgo, disponível em <http://www.lhn.uni-hamburg.de/>. 6 "(...) a semiotic phenomenon that transcends disciplines and media" 7 "There are, quite simply, meanings that are better expressed visually or musically than verbally."
} 
mas também os mundos em que esses eventos ocorrem são descritos.

Um dos assuntos que interessam à narratologia é a narrativa transmídia, ou seja, a relação entre a narrativa e as diversas mídias. A narratologia examina comparativamente como as diferentes mídias constroem a narrativa, considerando as limitações e possibilidades de cada mídia. Para Ryan, a narrativa transmídia é uma modalidade especial da transficcionalidade, definida por Richard Saint-Gelais como uma relação que se observa quando "dois (ou mais textos) (...) compartilham elementos tais como personagens, lugares imaginários, ou mundos ficcionais" (RYAN, 2013, p. 362). ${ }^{8}$ A diferença é que a transficcionalidade poderia também tratar de uma migração entre diferentes textos pertencentes a uma mesma mídia; já na narrativa transmídia, essa migração ocorreria apenas entre mídias diferentes. Ou seja, a narrativa transmídia seria um caso especial de transficcionalidade.

\section{Como a narrativa transmídia conta histórias?}

Cada meio, ou mídia, possui um mecanismo e planos de expressão próprios, uma maneira de criar verdade, de suscitar e satisfazer desejos e de entreter. Assim, não apenas os contos da tradição oral, as histórias bíblicas, os romances e as peças de teatro, mas também os filmes, os programas de televisão, as histórias em quadrinhos, os jogos digitais, de RPG, os mais diversos formatos midiáticos digitais etc., todos possuem diferentes maneiras de contar histórias e também, independentemente da mídia utilizada, todos podem contar histórias mais ou menos interessantes ou comoventes. ${ }^{9}$

Em Hamlet no holodeck, Janet Murray fala sobre o uso das tecnologias para explorar e contar histórias de uma nova maneira. Com as recentes tecnologias, podemos rearranjar histórias, gerando novas variedades de entretenimentos narrativos. Entre os efeitos dos novos ambientes eletrônicos estão o desenvolvimento de formas de narrativas mais colaborativas, em que todos podem ser contadores de histórias, e a

8 "two (or more) texts (...) share elements such as characters, imaginary locations, or fictional worlds." 9 A capacidade de contar histórias inerente a cada mídia é algo em constante evolução. Um exemplo são os jogos de vídeo game, que passaram por um progresso técnico significativo, não limitado à qualidade gráfica. Observa-se uma evolução a partir de jogos quase que totalmente mecânicos, de repetição, sem uma história - como os de pingue-pongue, Tetris, jogo da velha -, para jogos com uma narrativa coerente e complexa e personagens multifacetados - como, por exemplo, L.A. Noir (2011), Max Payne (2012) e Tomb Raider (2013), entre vários outros. Ultimamente, há uma enorme semelhança da narrativa do jogo à narrativa fílmica, reforçada pelo uso de cutscenes, sequências em que jogador passa a ter pouco ou nenhum controle sobre o personagem e que revelam novas informações sobre o enredo ou sobre os personagens. 
criação de universos narrativos cada vez mais complexos. Curiosamente, essas alterações nos formatos narrativos em ambientes digitais provocam efeitos em formatos mais tradicionais, como romances, peças de teatro, novelas e filmes, que passam, por exemplo, a oferecer narrativas menos lineares, mais fragmentadas e mais participativas.

Uma das mudanças apontadas é a proliferação daquilo que a autora chama de histórias multiformes, nas quais "múltiplas versões podem ser geradas a partir da mesma representação fundamental" e que

Camila Augusta Pires de Figueiredo "frequentemente refletem pontos de vista diferentes sobre um mesmo acontecimento" (MURRAY, 2003, p. 51). Além disso, a narrativa multiforme "procura dar uma existência simultânea às possibilidades, permitindo-nos ter em mente, ao mesmo tempo, múltiplas e contraditórias alternativas" (Ibidem). Isso acontece com bastante frequência nas histórias em quadrinhos, que exploram universos alternativos nos quais seus famosos super-heróis seguem por caminhos diferentes daqueles amplamente conhecidos como sua história verdadeira ou original.

Outra mudança apontada por Murray deriva da infinita capacidade que o computador nos oferece de acesso e de arquivo de informações, muitas vezes necessária para abrigar as múltiplas perspectivas da narrativa contemporânea:

\footnotetext{
Computadores são o meio de maior capacidade jamais inventado, prometendo recursos infinitos. [...] A capacidade enciclopédica do computador e a expectativa enciclopédica por ele gerada fazem dele um meio instigante para a arte narrativa. A capacidade de representar enormes quantidades de informação em formato digital traduz-se no potencial artístico de oferecer uma riqueza de detalhes, de representar o mundo tanto de modo abrangente quanto particular. [...] Ela oferece aos escritores a oportunidade de contar histórias a partir de múltiplas perspectivas privilegiadas, e de brindar o público com narrativas entrecruzadas que formam uma rede densa e de grande extensão. (Ibidem, p. 88-89)
}

Esse ambiente enciclopédico oferece as condições necessárias para a "imersão" do indivíduo na narrativa, a fim de tentar buscar todas as informações disponíveis sobre aquela história. E, quanto mais imerso nesse universo narrativo, mais participativo se deseja ser dentro dele. $\mathrm{O}$ ambiente eletrônico oferece espaço para participações individuais e 
coletivas, que podem ser ou não restringidas pelos criadores da narrativa. Entretanto, essa mesma característica enciclopédica, tão particular da tecnologia digital, também pode revelar um grande problema. Tanta informação dispersa em rede pode acabar confundindo o público ou ainda saturando-o com informações em excesso. Além disso, nem toda narrativa possui uma estrutura que exige um universo enciclopédico de detalhes sobre o enredo, sobre os personagens e o mundo ficcional.

Para descrever o novo ambiente narrativo contemporâneo, Murray utiliza a metáfora do caleidoscópio de Marshall McLuhan: ao contrário, por exemplo, da estrutura linear do livro impresso, os atuais meios de comunicação se parecem mais com mosaicos. Isso se reflete na visão de mundo que passamos a ter, não mais atrelada a um só ponto de vista. Apesar disso, "retemos o desejo humano

Narrativa Transmídia: modos de narrar e tipos de histórias fundamental de fixar a realidade sobre uma tela apenas, de expressar tudo o que vemos de modo integrado e simétrico" (Ibidem, p. 159). A solução para satisfazer a esse desejo humano, segundo a autora, seria a tela caleidoscópica do computador, capaz de apreender o mundo sob várias perspectivas.

Neste aspecto, creio que os últimos anos têm mostrado um panorama ligeiramente diferente. Uma vez que não apenas o computador, mas muitas outras mídias têm exibido qualidades caleidoscópicas, a realidade não se encontra mais fixada em um só lugar; ela deixa de pertencer a uma tela apenas para pertencer a várias ao mesmo tempo. Ainda assim, o desejo humano fundamental, de ver tudo de modo integrado e coerente, permanece o mesmo. É nesse sentido que a transmídia, ao capturar as perspectivas disponíveis em múltiplas telas e uni-las em uma narrativa coesa e coerente, capaz de satisfazer às ambições humanas, vem colaborar para a construção de uma visão de mundo ampliada.

Na transmídia, a compreensão da narrativa se dá no cruzamento de várias mídias, em um sistema de rede inter e multitextual que gerará uma experiência interpretativa ampliada e complexa. Esta é, aliás, uma das características preponderantes do fenômeno transmidiático, como também reconhece Li Xiaochang:

Talvez uma das maiores possibilidades de histórias transmidiáticas seja que elas operam não como uma coleção de textos, mas como um intertexto, um texto que é produzido na interação entre múlti- 
plos textos. Isso é parte do que diferenciam as transmídias, mídias que se movimentam cruzando formas e plataformas ou se colocando entre elas, de tramas multimidiáticas estáticas. A transmídia não se ocupa apenas de múltiplas histórias ou versões, mas de criar um rico espaço intermediário, um arquivo do sentido compartilhado entre diferentes partes da história. (XIAOCHANG, 2009) ${ }^{10}$

\section{Que tipos de história a narrativa transmídia conta?}

\section{Camila Personagens}

Augusta Pires de Figueiredo

Em seu livro, Jenkins afirma que, para criar um projeto transmidiático, é necessário um mundo ficcional de grandes proporções e detalhes, além, é claro, de uma boa história e de um bom personagem (JENKINS, 2009, p. 162). Mas o que significa ter um bom personagem?

Segundo Umberto Eco, a qualidade do personagem é percebida pelas emoções que ele suscita. Isto é, bons personagens evocam uma resposta emocional por parte do leitor. Essa resposta emocional, manifestada na catarse aristotélica, "depende de nossa identificação com os heróis do drama trágico, de modo a que sintamos compaixão e terror quando testemunhamos o que lhes sucede" (ECO, 2013, p. 67). Contudo, o fato de nos emocionarmos com certo personagem não está relacionado apenas aos seus atributos, mas também ao meio cultural em que nós, os leitores, nos inserimos. Isso porque a história e as características de um dado personagem podem sensibilizar mais alguns leitores, que interpretarão os atos dessa figura de maneira singular de acordo com seus hábitos e expectativas culturais. Ou, nas palavras de Eco:

\footnotetext{
Um personagem de ficção é por certo um objeto semiótico. Com isso quero dizer um conjunto de propriedades registrado na enciclopédia de uma cultura e veiculado por determinada expressão. Essas propriedades podem, por sua vez, ser interpretadas por outras expressões; e a série dessas interpretações inter-relacionadas constitui todas as noções relativas ao termo, as quais são partilhadas por uma comunidade e coletivamente registradas (Ibidem, p. 91-92).
}

\footnotetext{
10 No original: "Perhaps then one of the deep affordances of transmedia stories is that they operate just not as a collection of texts, but as an intertext, a text that is produced within the interaction between multiple texts. This is part of what differentiates transmedia, media that moves across and between forms and platforms, from static multimedia nodes [sic]. Transmedia isn't just about multiple stories or versions, but about creating a rich inbetween space, an archive of shared meaning inbetween different parts of the story."
} 
Alguns personagens de ficção extrapolam seus mundos, adquirindo uma existência independente dos textos nos quais foram criados, chamados por Eco de partituras. Essas figuras podem migrar de texto para texto, ao longo de séculos: trata-se de entidades "flutuantes". Em alguns casos, tais personagens se tornam mais conhecidos por seu "avatar extratextual do que no papel que desempenham em uma partitura específica", como, por exemplo, Chapeuzinho Vermelho, que, apesar de ter sido criada pelos irmãos Grimm, tornou-se popular com a história de Perrault (Ibidem, p. 89). Nesse caso, para cada um dos mundos possíveis para Chapeuzinho haverá uma expressão diferente para a personagem.

Isso também ocorre com Sherlock Holmes, personagem que, enquanto expressa propriedades específicas, também funciona como um Narrativa Transmídia: modos de narrar e tipos de histórias varal em que penduramos um conjunto de propriedades variantes. Assim, mesmo inserido em contextos diferentes, Holmes continua sendo Holmes desde que certas características sejam preservadas. Nesse caso, afirma Eco, "[s]eria interessante determinar quais notas podem ser descartadas sem destruir a Gestalt e quais, por outro lado, são essenciais ou diagnósticas - para a identificação da melodia" (Ibidem, p. 95). A análise dos atributos considerados essenciais para um personagem é uma reflexão útil para os casos de transmidialidade, em que há transferência de certas características midiáticas.

Marie-Laure Ryan sugere que um bom personagem ficcional é aquele que parece ter vida própria e que faz o público imaginar como ele agiria sob outras circunstâncias. E acrescenta que as histórias que possuem foco no enredo e não no personagem geralmente oferecem personagens com uma personalidade que não transcende os eventos nos quais participam (RYAN, 2013, p. 382). Isso é típico, por exemplo, das tragédias e dos contos de fada. Outro ponto defendido por Ryan é que, quando a narrativa cobre um longo período de tempo durante o qual o personagem passa por uma evolução psicológica, é mais difícil encontrar pontos de entrada para que novas histórias sejam inseridas no processo, pois essas histórias teriam que se encaixar, de alguma forma, no processo de evolução do personagem. Isso explicaria a preferência em utilizar, em projetos transmidiáticos, personagens que não evoluem de um episódio para outro, como os super-heróis dos quadrinhos, Indiana Jones ou James Bond. Nesse caso, Ryan diz que "o mundo ficcional se desenvolve através da acumulação de episódios que seguem um 
esquema narrativo padrão e infinitamente repetitivo, o padrão dos problemas individuais resolvidos pelo herói. O mundo ficcional fica cada vez maior, mas não muda significativamente." (Ibidem, p. 382-383) ${ }^{11}$

Assim, ao que parece, as narrativas episódicas são amplamente favorecidas nos processos transmidiáticos. Embora seja preciso dizer que nem todo projeto transmidiático tem uma estrutura episódica, os formatos serializados parecem ter uma certa predisposição para a transmídia. É por causa de seu formato serializado que, segundo Henry Camila Jenkins, a transmídia funciona tão bem com a televisão, já que o público Augusta Pires pode "embarcar" na história em diferentes pontos da narrativa. Além de Figueiredo disso, a estrutura televisiva permite que o público tenha um tempo entre episódios para buscar outros produtos relacionados à franquia.

É importante lembrar que nem todas as histórias que possuem bons personagens podem ou devem ser transformadas em projetos transmidiáticos. Em seu blog, Bordwell questiona o uso irrestrito da transmídia que pode levar o público a uma experiência monótona e "enlouquecedora":

\footnotetext{
Será que todo filme de terror precisa de um caminho em ziguezague de páginas da internet? Você quer um diário sobre o tempo livre do Demolidor? Você quer olhar a página do Flickr da família da Pequena Miss Sunshine? Você quer receber Tweets da Juno? Seguida ao máximo, a narrativa transmídia pode ser tanto monótona quanto enlouquecedora como sua própria vida. (BORDWELL, 2009) ${ }^{12}$
}

\section{Mundo ficcional}

O outro elemento que Jenkins menciona é a presença de um mundo ficcional de grandes proporções e detalhes, que consiga abarcar boas histórias e bons personagens. Mas o que seria o mundo ficcional e quais seriam suas características? Para Mark J. P. Wolf, professor do Departamento de Comunicação da Concordia University Wisconsin, o termo "mundo" não é utilizado apenas no sentido geográfico, mas no sentido da experiência, designando o conjunto das experiências de um perso-

11 “(...) the storyworld develops through an accumulation of episodes that follow a standard and infinitely repeatable narrative pattern, the pattern of the individual problems solved by the hero. The storyworld gets bigger and bigger, but it does not really change in meaningful ways."

12 "Does every horror movie need a zigzag trail of web pages? Do you want a diary of Daredevil's down time? Do you want to look at the Flickr page of the family in Little Miss Sunshine? Do you want to receive Tweets from Juno? Pursued to the max, transmedia storytelling could be as alternately dull and maddening as your own life." 
nagem relacionadas à cultura, natureza, visões filosóficas, lugares, costumes, eventos etc. Essas experiências podem ocorrer através de várias mídias que, de maneira combinada, fornecem ao público um sentido completo do mundo e daquilo que acontece nele (WOLF, 2012, p. 2).

Já Marie-Laure Ryan inclui na sua concepção a interpretação que cada indivíduo faz do mundo de um determinado texto ou conjunto de textos. Para a autora, o mundo ficcional consiste em "simulações mentais do desenvolvimento da história"13 construídas a partir da experiência do indivíduo com o(s) texto(s) e é formado por componentes espaçotemporais que podem ser estáticos ou dinâmicos. Os componentes estáticos seriam todos aqueles relacionados ao espaço geográfico - personagens, plantas, animais, objetos e instituições sociais que habitam o mundo ficcional - bem como o folclore, leis naturais, regras e valores

Narrativa Transmídia: modos de narrar e tipos de histórias sociais daquele lugar. Os componentes dinâmicos designariam os eventos físicos e mentais que influenciariam as relações sociais ou entre personagens existentes (RYAN, 2013, p. 364).

Segundo Ryan, o mundo ficcional deve possuir características invariáveis, para que possa ser reconhecido em diferentes mídias. Além disso, ele precisa ser amplo o suficiente para que possa refletir a diversidade de seus personagens, cenários e tramas em diferentes mídias. Isso quer dizer que ele deve possibilitar que várias histórias sejam contadas dentro da mesma narrativa. Cada personagem tem sua própria história; eles participam de eventos em determinados cenários e estabelecem relações com outros personagens. Os novos elementos incluídos na história - personagens, cenários, eventos abrem novas possibilidades para que a narrativa se expanda.

$\mathrm{Na}$ verdade, observa-se que em muitos projetos transmidiáticos de sucesso, muito mais do que narrar uma história em várias mídias, há um esforço em criar mundos ficcionais, especialmente quando ambientados em lugares fantásticos ou distópicos. De fato, uma vez que as histórias implicam um determinado tempo, espaço e causalidade, toda história obrigatoriamente transcorre em um mundo. Por outro lado, os mundos não dependem de estruturas narrativas para existirem. Assim, o mundo poderia existir sem uma história, mas não o oposto:

13 “(...) mental simulations of the development of the plot." (Ryan, Transmedial Storytelling and Transfictionality.) Dudley Andrew sugere que a construção mental do mundo ficcional é um processo desenvolvido intertextualmente que pertence tanto ao leitor quanto ao autor, e acrescenta que "[u]m dos objetivos da interpretação sempre foi o de fazer coincidir o mundo do leitor com o do autor". [One goal of interpretation has always been to make coincide the world of the reader with that of the writer.] (ANDREW, 1984, p. 39) 
Seja através de descrição verbal, design visual, design de som ou espaços virtuais revelados através de interação, é o mundo (às vezes chamado de mundo ficcional [storyworld] ou mundo diegético) que sustenta todas as narrativas e que está constantemente presente durante a experiência do público. E essa experiência pode ou não incluir a narrativa" (Ibidem, p. 16-17). ${ }^{14}$

Entretanto, o mais comum é que história e mundo ficcional tra-

Camila Augusta Pires de Figueiredo balhem juntos para oferecer experiências mais ricas para o leitor, e geralmente isso se dá, de acordo com Wolf, através de momentos em que a narrativa é "pausada" para que informações sobre o mundo e seus habitantes possam ser dadas (Ibidem). É importante compreender que é possível haver uma experiência transmidiática de mundo sem que as narrativas de uma determinada franquia estejam entrelaçadas.

Além disso, o mundo ficcional é um aspecto que merece atenção porque suas características facilitam a continuidade em projetos transmidiáticos. Uma proposta que descreve as principais características dos mundos ficcionais é a de Lisbeth Klastrup e Susana Tosca, do Centro de Pesquisa de Jogos de Computador da Universidade Técnica de Copenhagen. O mundo ficcional, chamado de mundo transmidiático, é produto da imagem mental que a audiência e os designers fazem de uma "mundanidade" [worldliness], um conjunto de características específicas desse universo. Essas características podem ser divididas em três categorias: mythos, topos e ethos, que correspondem aos elementos estáticos de Ryan. O mythos descreve todas as lendas, conflitos e batalhas por meio dos quais personagens e criaturas desse mundo são apresentados a nós. É o “pano de fundo", o conhecimento básico que precisamos ter para que possamos interagir ou interpretar eventos de modo apropriado nesse mundo. Topos se refere ao "cenário de um mundo em um período histórico específico e a uma geografia detalhada" (KLASTRUP; TOSCA, 2004, p. 412). ${ }^{15} \mathrm{O}$ espaço e o tempo de um universo são normalmente imutáveis, mas não há impedimentos para que atualizações desse mundo possam ocorrer, por exemplo, em algum ponto no tempo antes ou depois daquele já explorado ante-

14 "Whether through verbal description, visual design, sound design, or virtual spaces revealed through interaction, it is the world (sometimes referred to as the storyworld or diegetic world) that supports all the narratives set in it and that is constantly present during the audience's experience. And that experience may or may not include narrative."

15 “(...) the setting of the world in a specific historical period and detailed geography." 
riormente, desde que essas atualizações não interfiram no mythos. Finalmente, o ethos se refere à "ética explícita e implícita do mundo e o código (moral) de comportamento, que devem ser seguidos pelos personagens" (Ibidem). ${ }^{16}$ Após a análise de alguns exemplos de mundos transmidiáticos, Klastrup e Tosca afirmam que manter-se fiel ao mythos, ao topos e ao ethos de um mundo ficcional ajuda a assegurar uma resposta positiva por parte do público para, por exemplo, uma adaptação (Ibidem, p. 215).

Nota-se que a taxonomia de Klastrup e Tosca omite os eventos da história, assim como a concepção de Wolf, que estabelece uma distinção entre o desenvolvimento do mundo ficcional - que ocorre principalmente através de descrição (ou mostração [monstration], para usar o termo de Thierry Groensteen (1990, p. 18), em relação às mídias visuais) - e o desenvolvimento da narrativa - através da sequencialidade dos

Narrativa Transmídia: modos de narrar e tipos de histórias eventos da história. Isso porque as autoras focam mais no ponto de vista de uma representação mental do universo ficcional do que em uma abordagem que privilegia os eventos narrativos. Assim, o mundo ficcional é parte relevante da transmídia - e, dependendo da abordagem, algo indissociável dos eventos narrativos.

\section{Verossimilhança}

Além de um grande mundo ficcional, com personagens marcantes, e do formato serializado, há uma tendência de que as histórias narradas por meio de práticas transmidiáticas empreguem estratégias de verossimilitude ou verossimilhança. Trata-se de um termo que descreve elementos que simulam a vida real. $\mathrm{Ou}$, em outras palavras:

[a] verossimilhança se refere à sugestão de que objetos no mundo ficcional possuem propriedades que objetos semelhantes teriam no mundo exterior vivenciado pelo autor e pelo leitor. Caso um mundo ficcional tenha verossimilhança, as relações temporais e espaciais são as mesmas que alguém encontraria em um mundo real. (SEGAL apud DENA, 2009, p. 284) $)^{17}$

\footnotetext{
16 "(...) the explicit and implicit ethics of the world and (moral) codex of behaviour, which characters in the world are supposed to follow."

17 "Verisimilitude refers to the suggestion that the objects in the story world have properties there that similar objects would have in the outside world experienced by the author and reader. To the extent that a story world has verisimilitude, temporal and spatial relations are the same as one would be likely to find in the real world."
} 
Uma das maneiras de tornar a história mais realista é simular a utilização de mídias pelos personagens. Eles usam as mídias sociais Facebook, Twitter, Instagram etc. -, blogs pessoais e emails para fazer comentários relacionados à narrativa e conversar com os fãs. Assim, além de promoverem a interação com o público, eles confundem as fronteiras entre o mundo ficcional e o real. Outra maneira de atingir isso é promover crossovers - numa tradução um pouco literal "encontros cruzados" - entre personagens de diferentes programas de televisão, filmes, Camila séries etc. Finalmente, temos uma ilusão de um mundo real quando um Augusta Pires de Figueiredo livro tem sua autoria creditada a um personagem ficcional.

Além disso, entre as práticas mais comumente empregadas em projetos transmidiáticos que simulam o mundo real estão os jogos de realidade alternativa - ou simplesmente ARGs, alternate reality games. Os ARGs são jogos em que várias mídias - redes sociais, emails, lugares reais, telefones, websites, por exemplo - são usadas com o intuito de fazer os fãs seguirem caminhos ou pistas, ou solucionarem quebra-cabeças que acrescentam informações à história. A diferença entre um jogo tradicional e um ARG é que neste há uma tentativa de apagamento entre o que é autêntico (pertencente ao mundo real) e a simulação, por meio da inclusão do mundo real dentro do ficcional, situação que é muitas vezes expressa pela conhecida frase "This is not a game" [Isto não é um jogo], ou pela sua abreviatura TINAG. Essa frase ficou famosa ao surgir ao final do trailer do filme A.I.: Inteligência Artificial (2001), de Steven Spielberg, e faz parte do jogo chamado The Beast, citado até hoje como um dos ARGs de maior sucesso na indústria do entretenimento.

No Brasil, um caso alcançou grande repercussão pela bem-sucedida empreitada de ultrapassar as fronteiras do real e do fictício. Em 2007 o então senador Arthur Virgílio proferiu um discurso no plenário contra um vídeo divulgado na internet a respeito de uma suposta empresa norte-americana, a Arkhos Biotech, que propunha a privatização da Amazônia, a fim de transformá-la em um santuário de preservação sob o controle privado. 0 site da empresa, mencionado no vídeo, ${ }^{18}$ apresentava a história e os produtos daquele que seria um dos maiores fabricantes de ativos vegetais para a indústria cosmética e farmacêutica. Entretanto, tanto o site quanto o vídeo faziam parte

18 ARKHOS Biotech - legendado. Disponível em: <https://www.youtube.com/watch?v=LPrdeL2Lr98>. Acesso em: 14 jan. 2016. 
de um ARG patrocinado pelo Guaraná Antarctica, cujo objetivo era que os jogadores ajudassem a proteger a fórmula do famoso refrigerante, ameaçada pela falsa empresa americana.

É inegável, portanto, que existem certos princípios que norteiam a escolha do conteúdo de acordo com a forma, ou seja, caso se pretenda desenvolver um projeto transmidiático, tende-se a escolher histórias que: a. se situem em um mundo ficcional rico em detalhes; $b$. tenham bons personagens e uma estrutura episódica; e/ou c. possibilitem a busca por verossimilitude.

Narrativa Transmídia: modos de narrar e tipos de histórias para serem representadas através de projetos transmidiáticos são aquelas em que há aspectos mitológicos ou icônicos envolvidos, como arquétipos de histórias populares do entretenimento ou figuras amplamente conhecidas por serem ícones culturais.

A presença do mito é constante em produções culturais contemporâneas, e a pluralidade de mídias hoje disponíveis fornece ferramentas para que narrativas orais antigas sejam revisitadas e transformadas de acordo com o contexto social atual. Os mitos estão relacionados a temas que buscam explicar aspectos da vida humana, da criação de civilizações, de religiões; entre eles pode-se citar a jornada do herói, em que o protagonista recebe um chamado à aventura, mas passa por testes e provações antes de alcançar seu objetivo. Trata-se de uma estrutura narrativa cujos elementos são facilmente identificados em vários produtos culturais como novelas, filmes e séries de televisão e que já está profundamente arraigada no subconsciente e no imaginário humano. A utilização de estruturas mitológicas em projetos transmidiáticos causa um efeito que remete ao da adaptação, pois há já uma certa "familiaridade do público com essa estrutura básica de enredo", o que "permite aos roteiristas omitir sequências transicionais ou expositivas, jogando-nos direto no centro da ação" (JENKINS, 2009, p. 173).

Figuras icônicas são escolhas comuns para personagens de franquias transmidiáticas pela sua familiaridade com o público. Isso quer dizer que possivelmente existem textos prévios que construíram o ícone. Em muitos casos, esse processo ocorre ao longo de vários anos e talvez não haja um significado completamente estável para essa figura. Nesse caso, o trabalho de rastrear as características midiáticas transferidas 
nos vários produtos da franquia torna-se uma tarefa extremamente complexa. A semiótica tem um papel importante na cultura visual, pois destrói "o comprometimento da história da arte com uma explicação da criação artística que é baseada na ideia da semelhança ou mímese" em favor de um "discurso semiótico ricamente feito da imagem" (BRYSON apud TOMASELLI; SCOTT, 2009, p. 14). ${ }^{19} \mathrm{O}$ foco, então, passa a ser na interação dos produtos culturais com uma rede ampla de "componentes intertextuais e intersemióticos que constituem qualquer tradição culCamila tural" (Ibidem) ${ }^{20}$ Entretanto, essa rede, baseada em negociações interAugusta Pires textuais elaboradas na mente do interator, é bastante complexa: não há de Figueiredo como estabelecer um padrão para o seu funcionamento, nem reduzi-la a uma distinção entre públicos familiarizados e não familiarizados com a narrativa, como bem resumiu Clare Parody em contexto de franquias:

[...] a maioria das franquias midiáticas apóia múltiplos pontos de entrada e rotas através da vastidão labiríntica de suas redes textuais e o mundo imaginado que elas mapeiam, tanto que o conhecimento do consumidor de uma franquia é mais bem compreendido em termo de um espectro do que de um binarismo. (PARODY, 2011, p. 213) ${ }^{21}$

Para Jens Eder, o processo de construção de sentidos que ocorre através do acesso consecutivo aos produtos culturais da franquia transmidiática é influenciado pela adição e sobreposição de elementos informativos e sensoriais de experiências midiáticas anteriores, que ficam guardadas na memória do interator. Esse processo de recepção, chamado por Eder de imaginação transmidiática, "envolve todos os níveis da experiência estética: percepção, construção do mundo representado, exploração de significados indiretos e reflexões comunicativas". (EDER,

19 “(...) art history's allegiance to an account of artistic creation that is based on the concept of resemblance or mimesis"; "richly textured semiotic discourse of the image"

20 “(...) intertextual and intersemiotic components that constitute any cultural tradition."

21 “(...) major media franchises support multiple points of entry into and routes through the labyrinthine vastness of their textual networks and the imagined world they map, such that consumer knowledge of a franchise source is better conceptualized in terms of a spectrum than a binary." Apesar de tratar especificamente de adaptações em sistema de franquias no trecho citado, as considerações de Clare se aplicam perfeitamente a qualquer franquia transmidiática. 
2015, p. 7 ${ }^{22}$ Isto é, as percepções do interator sobre certo produto se misturam à sua imaginação, formada pelas memórias de suas experiências anteriores com aquela marca ou franquia. Isso implica também que certas características devem ser preservadas para que o público possa reconhecer e aceitar um personagem ou uma história como parte da imaginação transmidiática daquela marca ou franquia. No caso do personagem Batman, por exemplo:

Narrativa

Transmídia:

Esses devem ser os princípios do comportamento do personamodos de gem (que o Batman nunca mata); regras ou fórmulas narrativas narrar e tipos (que o Coringa sempre escapa), leis do mundo ficcional, motivos de histórias visuais, verbais ou auditivos ou qualidades menos facilmente definidas de tom ou estilo. (...) também está em jogo a presença cultural e a relevância da marca de entretenimento, as formas pelas quais ela circula nos discursos culturais e na consciência coletiva, os significados e funções que adquire ao fazê-lo e as maneiras pelas quais é absorvida e apropriada pelos consumidores. (PARODY, 2011, p. 215) ${ }^{23}$

\section{Conclusão}

Observando as produções midiáticas contemporâneas na indústria do entretenimento, percebe-se que existem certas peculiaridades que se relacionam com as novas formas de se contar, recontar e consumir (ouvir/ver/assistir/jogar etc.) histórias. Tais mudanças resultam do crescente desenvolvimento de objetos midiáticos pertencentes a uma nova era de produtos culturais híbridos e imersos em redes textuais cada vez mais complexas.

Por meio de uma abordagem transmidiática, é possível incluir como objeto de estudo as extensões em outras mídias que suplementam uma narrativa principal ou que se suplementam mutuamente e que au-

\footnotetext{
22 “(...) involves all levels of the aesthetic experience: perception, construction of the represented world, exploration of indirect meanings, and communicative reflections."

23 "These may be tenets of character behavior (that Batman never kills); narrative rules or formulae (that the Joker always escapes) laws of worldbuilding, visual, verbal, or aural motifs; or less easily definable qualities of tone or style. (...) at play as well is the cultural presence and significance of the entertainment brand, the forms in which it circulates in cultural discourses and the collective consciousness, the meanings and functions it picks up as it does, and the ways in which it is absorbed and appropriated by consumers."
} 
xiliam na reverberação do conteúdo em outros ambientes midiáticos. Esse fenômeno transmidiático hoje pertence ao campo de estudo da narratologia, que reconhece a importância de examinar a narrativa em várias mídias, considerando-a uma representação mental e cognitiva.

Ao observar alguns casos de franquias transmidiáticas na atualidade, é possível concluir que: histórias que possuem personagens fortes - com os quais nos identificamos facilmente e que "adquirem um tipo de existência independente de suas partituras originais" (ECO, 2013. p.

Camila Augusta Pires de Figueiredo 87) -, que constroem um mundo ficcional verossímil e que possuem fortes aspectos mitológicos e icônicos são mais predispostas à transmidiação. Pode-se ainda afirmar que os elementos que costumam ser transferidos através de mídias no contexto de uma franquia transmidiática são os personagens, as características e a estética de mundos ficcionais (cenários e figurinos, por exemplo) e o enredo.

\section{REFERÊNCIAS BIBLIOGRÁFICAS}

ANDREW, Dudley. Concepts in Film Theory. New York: Oxford University Press, 1984.

BORDWELL, David. Now Leaving from Platform 1. 19 ago. 2009. Observations on Film Art. Disponível em: <http://www.davidbordwell. net/blog/2009/08/19/now-leaving-from-platform-1/>, acesso em 12 mar. 2015.

DENA, Christy. Transmedia Practice: Theorising the Practice of Expressing a Fictional World across Distinct Media and Environments. 2009. Tese (Doutorado em Cultura Digital). School of Letters, Art and Media, University of Sydney, Sydney, 2009.

ECO, Umberto. Alguns comentários sobre os personagens de ficção. In: Confissões de um jovem romancista. São Paulo: Cosac Naify, 2013. p. 63-108.

EDER, Jens. Transmediality and the Politics of Adaptation: Concepts, Forms, and Strategies. In: HASSLER-FOREST, Dan; NICKLAS, Pascal (ed.). The Politics of Adaptation: Media Convergence and Ideology. 
London: Palgrave Macmillan, 2015. p. 66-81.

EVANS, Elizabeth. Transmedia Television: Audiences, New Media and Daily Life. New York/London: Routledge, 2011.

GROENSTEEN, Thierry. Du 7e au 9e art: l'inventaire des singularités. CinémAction. Courbevoie, p. 16-28, été 1990. Hors série Cinéma et bande dessinée.

Narrativa

Transmídia:

modos de narrar e tipos de histórias Fan: The Official Weblog of Henry Jenkins, 1 ago. 2011. Disponível em: <http://henryjenkins.org/2011/08/defining_transmedia_further_re.html>, acesso em 04 mar. 2015.

KLASTRUP, Lisbeth; TOSCA, Susana. Transmedial Worlds: Rethinking Cyberworld Design. In: INTERNATIONAL CONFERENCE ON CYBERWORLDS. 2004. [Proceedings...] Disponível em: <http://www.itu. $\mathrm{dk} /$ people/klastrup/klastruptosca_transworlds.pdf>, acesso em 15 jul. 2015.

MURRAY, Janet. Hamlet no holodeck: o futuro da narrativa no ciberespaço. São Paulo: UNESP/Itaú Cultural, 2003.

PARODY, Clare. Franchising/Adaptation. Adaptation. Oxford, v. 4, n. 2, p. 210-218, 2011.

RYAN, Marie-Laure. Introduction. In: RYAN, Marie-Laure. (ed.), Narrative Across Media: The Languages of Storytelling. Lincoln: University of Nebraska Press, 2004. p. 1-40.

Narrative. In: HERMAN, David; JAHN, Manfred; RYAN, MarieLaure (ed.). Routledge Encyclopedia of Narrative Theory. Oxfordshire/ New York: Routledge, 2005. p. 344-348.

. Transmedial Storytelling and Transfictionality. Poetics Today. v. 34, n. 3, p. 361-388, 2013. 
TOMASELLI, Keyan G.; SCOTT, David. Introduction. In: TOMASELLI, Keyan G.; SCOTT, David (ed.). Cultural Icons. Walnut Creek: Left Coast Press, 2009.

WOLF, Mark J. P. Building Imaginary Worlds: The Theory and History of Subcreation. New York/Oxon: Routledge, 2012.

XIAOCHANG, Li. Transmedia as Intertext and Multiplicity: Why Some Camila Types of Stories Lend Themselves to Transmedia. 23 set. 2009. In: Augusta Pires Canarytrap.net: Dis/junctures of Digital Media, Globalization, and de Figueiredo Consumer Culture. Disponível em: <http://canarytrap.net/2009/09/ transmedia-as-intertext-and-multiplicity-why-some-types-of64 -stories-lend-themselves-to-transmedia/>, acesso em 06 jan. 2016.

Recebido em 13 de maio de 2016 Aceito em 07 de agosto de 2016 